(REVIEW ARTICLE)

\title{
Pharmaceutical procurement practice aspects
}

\author{
Abdrhman Mahmoud Gamil * \\ Faculty of Pharmacy, Al-Neelain University, Sudan Associate Professor of Pharmaceutics.
}

Publication history: Received on 13 December 2020; revised on 20 December 2020; accepted on 22 December 2020

Article DOI: https://doi.org/10.30574/wjarr.2020.8.3.0489

\begin{abstract}
Procurement is the most important part of the pharmaceutical logistic cycle. It is the process of acquiring supplies after a properly selected list of products. The procurement system or model depends on the type of organization weather it is governmental or private, centralized or decentralized, autonomous or semiautonomous. The objectives of procurement system is to make available the right drug in an appropriate quantities of adequate quality from a reliable supplier at the right time with the lowest possible prices through an ethical and legal procedures. Prequalification of suppliers is the successful quality assurance activity. Needs and funds can be reconciled and a rational cut can be done by using ABC-VAN matrix technique. Purchasing should be by transparent competition through open tender, restrictive tender, restricted competition or in certain cases by direct negotiation by transparent committee leading to transparent contract. One of the most important procurement practice for the system to succeed is the reliable payment and efficient financial management and monitoring the supplier performance. The system should have an efficient quality assurance program with annual auditing and regular reports.
\end{abstract}

Keywords: Good Pharmaceutical Procurement Practice; Pharmaceutical procurement strategies; Qualification of suppliers; Quantification of medicines; ABC-VEN analysis; Reconciling needs and funds.

\section{Introduction}

Medicines supply is the most important pharmaceutical practices issue as all the pharmaceutical disciplines are parts of the supply system. Improved management is corner stone for any supply system to succeed. Drug logistics is the science and art of bringing the right drug in the right time to the right place in appropriate quantities to satisfy the health demands. It involves all the processes required to bring medicines from the manufacturer to the dispenser and ultimately to the individual patient [1].

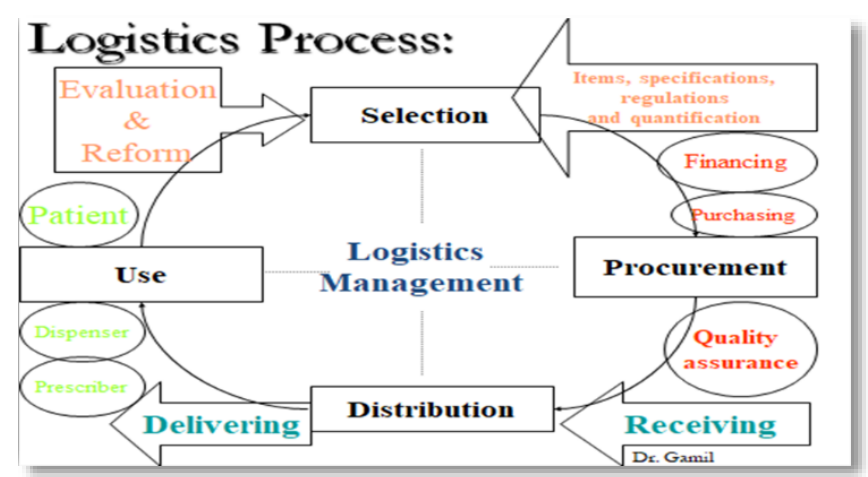

Figure 1 The Pharmaceutical Logistics Cycle.

\footnotetext{
* Corresponding author: Abdrhman Mahmoud Gamil. Faculty of Pharmacy, Al-Neelain University, Sudan Associate Professor of Pharmaceutics. Email: abdrhmangamil@gmail,com 


\section{Procurement Systems}

Procurement is the process of acquiring supplies. The Pharmaceutical Procurement Systems are directly related to the type of the pharmaceutical supply organization. The procurement models depend on the national economy of the country. The system organization may be centralized, decentralized or directorate models. It may be central medical supplies, aautonomous or semiautonomous supply system, direct delivery system, prime- vendor system, fully private system and mixed systems.

Procurement systems are sorted according to the type of the organization except that many organizations may practice the process collectively in one procurement office known as a pooled procurement. A worldwide belief that group purchasing through one procurement office continues to offer clear advantage over decentralized procurement in that:

- $\quad$ Reduces prices to the lowest possible rates.

- $\quad$ Reduces the cost of management.

- Guarantees payment encourages suppliers to compete in price and performance but, the process is a time consuming and if one of the group members failed to fulfill his commitment, the program may fail for the whole group.

\subsection{Objectives of procurement}

Making available the right drugs in the right quantities of assured quality in the right time and having the lowest possible prices from a reliable supplier, (best value for money). Safety stock should be maintained. These objectives should be achieved in a legal and ethical manner.

\subsection{Procurement methods}

The procurement methods can be compared as follows:

Table 1 Comparison between procurement methods

\begin{tabular}{|c|c|c|c|c|}
\hline Method & Open tender & $\begin{array}{l}\text { restricted } \\
\text { tender }\end{array}$ & $\begin{array}{l}\text { competitive } \\
\text { negotiation }\end{array}$ & direct purchase \\
\hline Suppliers & Open for all suppliers & $\begin{array}{l}\text { Pre-qualified } \\
\text { suppliers }\end{array}$ & Limited suppliers & Single suppliers \\
\hline Competition & Open & $\begin{array}{l}\text { Open and } \\
\text { negotiated }\end{array}$ & $\begin{array}{l}\text { Negotiation and } \\
\text { bargaining }\end{array}$ & Quoted prices \\
\hline Prices obtained & Lowest prices & Favourable & Can be favourable & Highest prices \\
\hline Lead time & Long & Moderate & Moderate & Short \\
\hline Work load & High & High & Moderate & Low \\
\hline Conditions & $\begin{array}{l}\text { Many suppliers } \\
\text { available } \\
\text { No pre-qualification } \\
\text { Bulk quantities } \\
\text { Large facilities and } \\
\text { open supply channels }\end{array}$ & $\begin{array}{l}\text { List of registered } \\
\text { supplier. } \\
\text { Good supplier } \\
\text { monitor } \\
\text { Certain standards } \\
\text { of quality }\end{array}$ & $\begin{array}{l}\text { Qualified export office } \\
\text { needed } \\
\text { Market intelligence } \\
\text { Small quantities of low } \\
\text { prices } \\
\text { Items are not widely } \\
\text { available } \\
\text { Long- term supply }\end{array}$ & $\begin{array}{l}\text { Other methods are } \\
\text { not possible } \\
\text { Emergency } \\
\text { Single sources } \\
\text { Non-profits } \\
\text { supplier }\end{array}$ \\
\hline
\end{tabular}

Mixed methods could be done; large and bulk quantities for open or restricted tender, small quantities of low prices by competitive negotiation, direct negotiated purchases for emergencies and when non-profit agency exists [2]. 


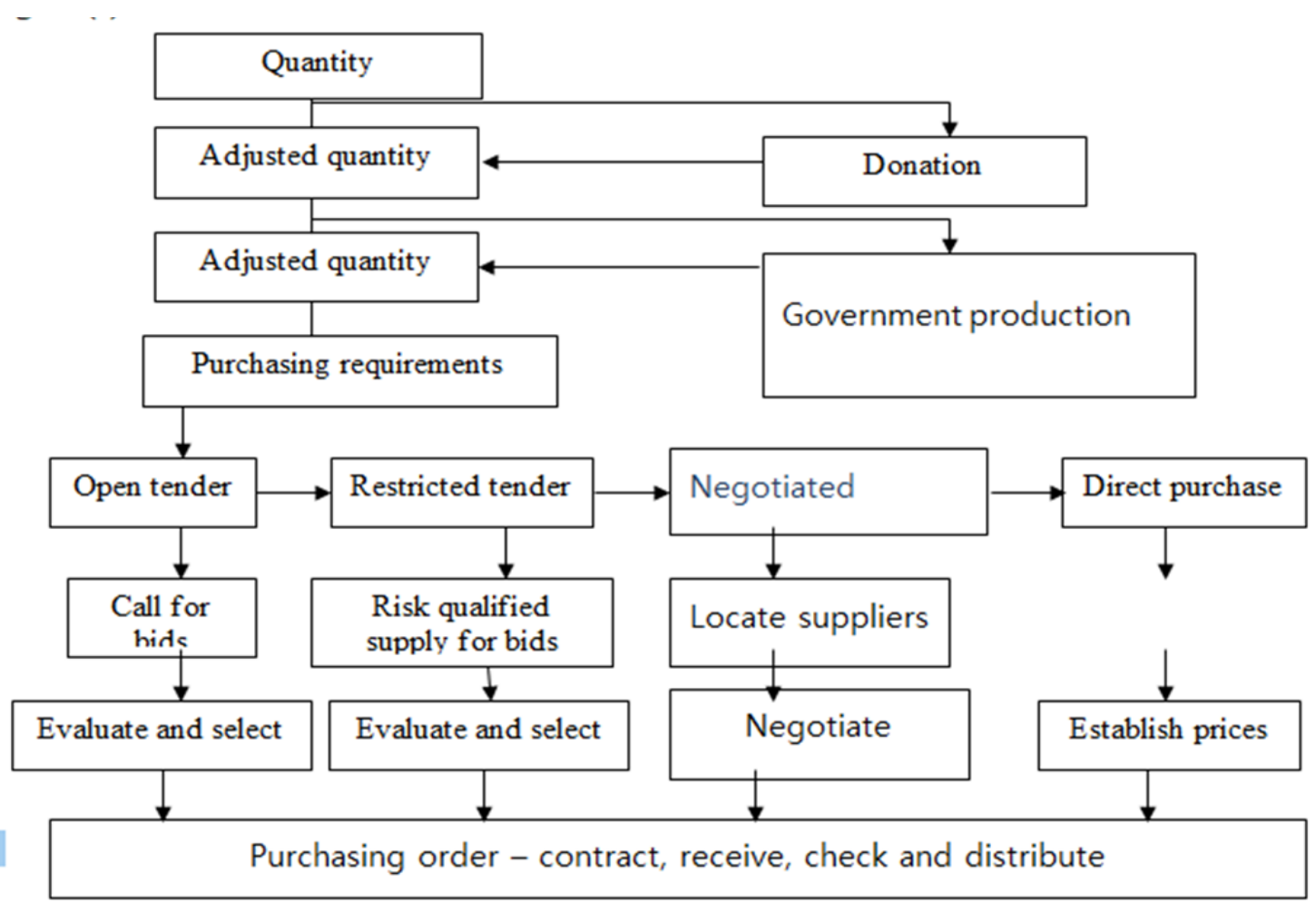

Figure 2 The general procurement decisions [2]

\section{Procurement cycle}

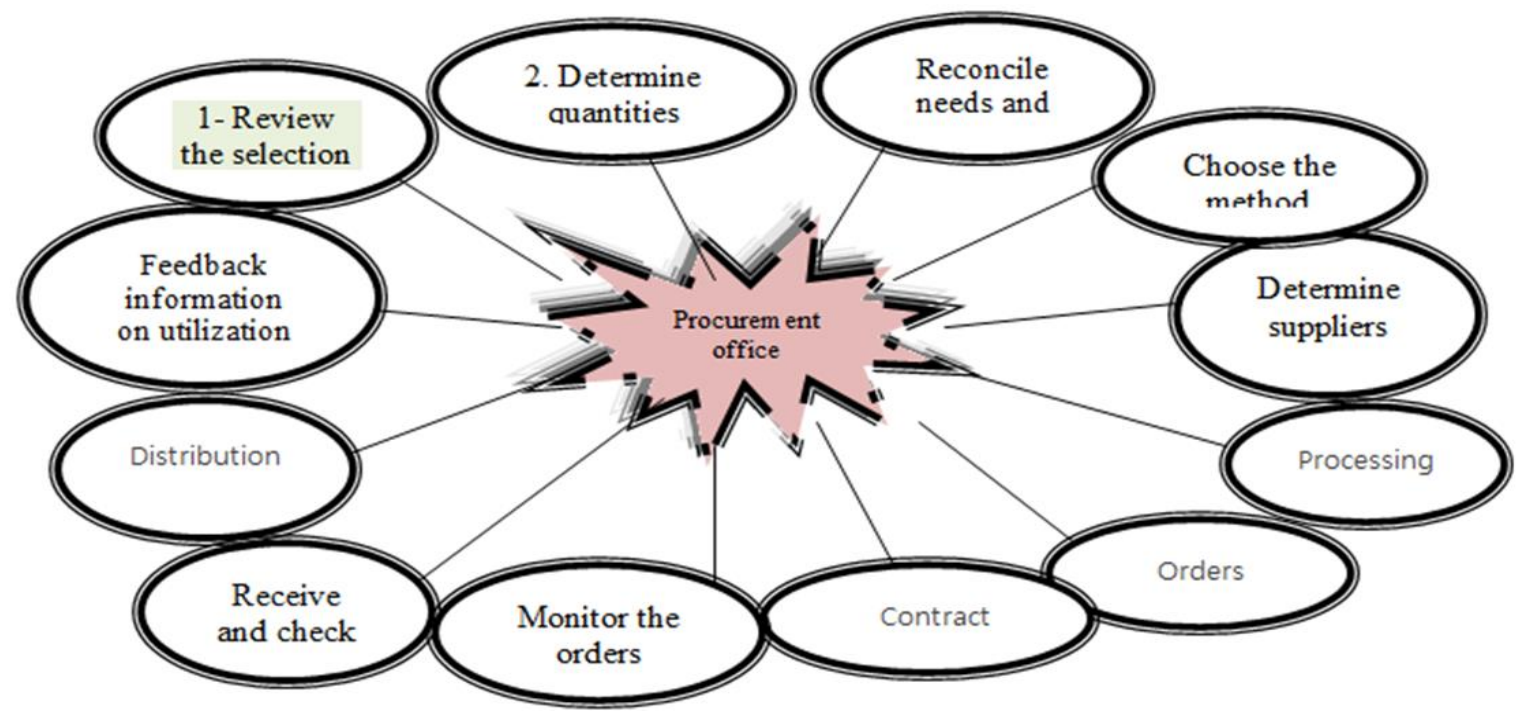

Figure 3 The procurement cycle

The procurement office is the directing force of the cycle and planning various activities in a weekly time-table.

\subsection{Review the selected list of drugs}

The selection list is prepared by authorized committee specifying the generic name, dosage form, strength, basic unit, basic package size, basic package in the outer packets, specification of containers, proposed price for basic unit and any other specifications. 


\subsection{Quantification of Drugs}

Quantification could be centralized or decentralized. Quantities should be adjusted for:

- $\quad$ 1-Filling the supply pipeline: 12 months working stock + 2 months safety stock for the center. 3 months working stock +2 months safety stock for the regions, 3 months working stock +2 months safety stock for health center, one month working stock for dispensaries, a total of 25 months stock.

- 2-Adjusting for lead time: should be determined for each drug. It is the time from issuing an order to receiving the goods calculated in days.

- 3-Adjusting for losses, damage, expiration, spoilage and theft.

- 4-Adjusting for the growth of the program.

- 5-Adjusting for the outbreaks of epidemic and emergencies.

\section{Methods of quantification}

\subsection{A- Morbidity method: this method requires [3]}

Prefect, dependable accurate statistical data in diseases and health problems should be available together with treatment guidelines with approved manual defining the standard treatment. Percentage of each treatment regimen for diseases and number of treatment episodes with their age scale were the required data.

Formula: $\mathrm{Q}_{\mathrm{E}}$ quantity per episode $=\mathrm{D}_{\mathrm{cu}}$ (number of basic units per dose) $\mathrm{x}$ (number of daily doses) $\mathrm{x}$ LD number of days of treatment.

$$
\text { (Number of episode treated) ET }=\frac{\text { number of contacts X problem frequency }}{100}
$$

$\mathrm{P}_{\mathrm{T}}=$ percent treated

Total quantity $\mathrm{QT}=Q E \times E T \times P T$

\subsection{Problems related with this method [3]}

- Difficulty in obtaining the required data.

- Different treatment patterns and different prescribers and different regions.

- Could not be applied for more than 50-100 health problem.

- Difficult to be applied in a complex system of different health levels.

- It is a very generous method facing the limited funds. However, it is useful in budgeting and calculating the cost of treatment. It indicates the huge quantity of drugs required being useful to convince policy- makers on impossibility of free supply system.

\subsection{B-Consumption method}

This method is based on the data obtained from the bin card at the store level or at the health facility stores [4]. Calculated as follows:

$$
\begin{aligned}
& \text { Adjusted monthly consumption }=\frac{\text { Total consumption in a period }}{(\text { reviewed months }- \text { stock outs in months })} \\
& \qquad \mathrm{C}_{\mathrm{A}}=\mathrm{CT} /(\mathrm{RM}-\mathrm{MO})
\end{aligned}
$$

Adjusted for the safety stock $=\mathrm{C}_{\mathrm{A}} \mathrm{x}$ lead time $+\mathrm{SS}=\mathrm{C}_{\mathrm{A}} \times \mathrm{LT}$

This formula could be adjusted for vital items.

The quantity ordered $\mathrm{S}_{0}$ could be subtracted and also stock in hand $\mathrm{S}_{1}$ subtracted so the quantity required for a certain procurement period PP could be represented as:

$$
\mathrm{Q}_{0}=\mathrm{C}_{\mathrm{A}} \mathrm{x}(\mathrm{LT}+\mathrm{PP})+\mathrm{SS}-\left(\mathrm{S}_{1}+\mathrm{S}_{0}\right)
$$


Then it could be adjusted for changes in utilization, prescribing and seasonality, out breaks, losses and theft.

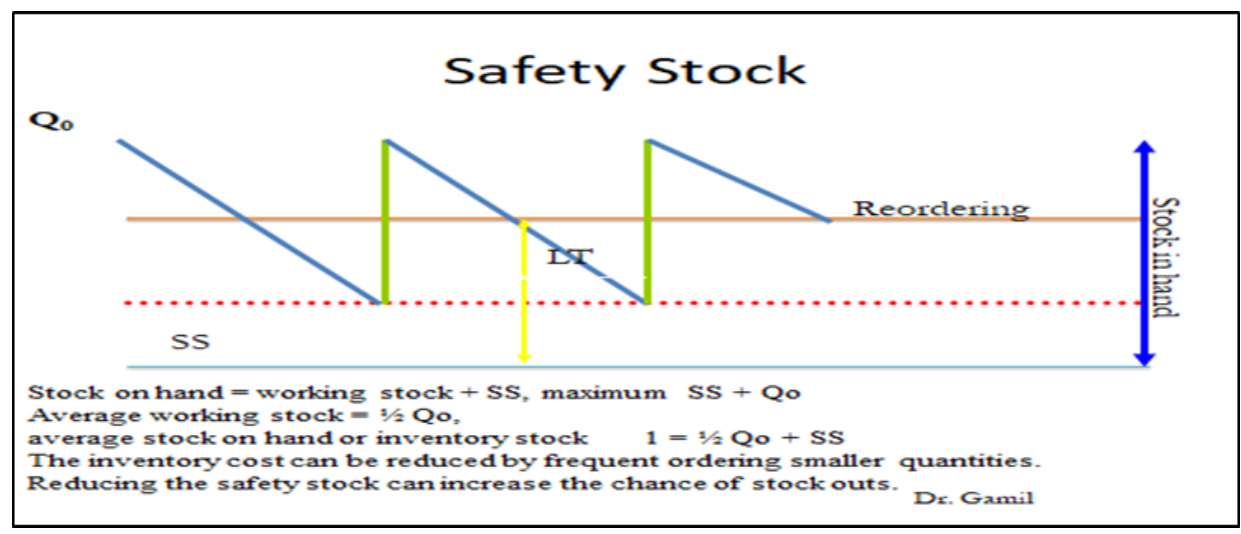

Figure 4 Safety stock Diagram

\subsection{C-Adjusted consumption method: (population or service based estimates) ${ }^{3}$.}

Select a standard reference system having a good morbidity and population data. Then the annual consumption was calculated. Dominator was selected, either 1000 of inhabitants or 1000 of patient contact.

The rate of consumption will be the annual consumption divided by the number of thousands of inhabitants or number of thousands of patient contact. On extrapolation to other target system, the number of thousands of inhabitants or contacts according to reference rate multiplies the annual rate of consumption.

Table 2 Population based estimate method, working sheet.

\begin{tabular}{|c|c|c|c|c|c|c|c|c|}
\hline \multicolumn{9}{|c|}{ Reference system of known inhabitant, known contact number and available data } \\
\hline \multicolumn{3}{|l|}{ Drug } & \multicolumn{3}{|c|}{ Consumption } & \multicolumn{3}{|c|}{ Rate of consumption } \\
\hline Name & Strength & Unit & Total & $\begin{array}{l}\text { Stock- } \\
\text { out } \\
\text { period }\end{array}$ & $\begin{array}{l}\text { Adjusted } \\
\text { consumption }\end{array}$ & $\begin{array}{l}\text { Average } \\
\text { annual } \\
\text { Consumption }\end{array}$ & $\begin{array}{l}\text { Consumption } \\
\text { per } 1000 \\
\text { inhabitants }\end{array}$ & $\begin{array}{l}\text { Consumption } \\
\text { per } 1000 \\
\text { contacts }\end{array}$ \\
\hline \multicolumn{9}{|c|}{ Target system of known inhabitant, unknown contacts and data not available } \\
\hline \multicolumn{5}{|c|}{ Projected requiremnts for? inhabitants } & Unit price & Value & \multicolumn{2}{|c|}{ Remarks } \\
\hline
\end{tabular}

If the morbidity data and consumption records are available regionally and centrally, both methods of morbidity and consumption could be done and compared with the central records and a rational value could be obtained [5].

\section{Reconciling Needs and funds [6]}

The total value of the cost of drugs being calculated should be reconciled with the available funds.

If the cost of drugs exceeds the available funds, the selection list, prescribing patterns, theft, losses and good procurement monitoring factors may be considered.

Then the cost effective dosage form is selected, and if quantities should be cut, it should be systematic. Equal cut across all items is not reasonable. Disease priorities, age group priorities, health facilities priorities could be reviewed. If enforced to cut the quantities, the rational cut needs the analysis of the quantities according to the following tools:

- VEN analysis

- $\mathrm{ABC}$ analysis

- Price comparison analysis

- Therapeutic category analysis 
- Total variable cost analysis

- Lead time and payment analysis.

- Expiry date analysis.

- Hidden cost analysis

- Cross check with other systems or with the last year consumption.

\subsection{VEN system Analysis:}

Classification of drugs into vital, essential and nonessential is best to be done by an authorized expert committee or by the formulary committee or by the selection committee taking in consideration the occurrence of disease and its severity and the therapeutic effect of the drug. The population and prevalence of patient should also be considered, together with the degree of life threat and of course the cost of therapy.

\subsection{ABC Analysis:}

$\mathrm{ABC}$ analysis is categorizing the list into $\mathrm{ABC}$ according the value of their annual consumption. Descending sorting of the percentage of the annual consumption values is obtained and cumulative percentage is calculated plotting graphically the percentage against number of drugs.

A- (10-20\%) expend 75\% -80\% of the total value. B- (10-20\%): expend about $15-20 \%, \mathrm{C}-(60-80 \%)$, expend 5-10\% of the total value.

Special attention should be given to class A to protect from theft and losses and minimizing the lead time, daily monitoring and seeking for alternatives or decreasing the prices will significantly affect the budget $[7,8,9,10]$.

Actions should be made to category A by:

- $\quad$ Setting regulations and daily monitoring.

- Controlling consumption and inventory records.

- Increasing security measures.

- Looking for alternative procurement methods to obtain lower prices.

- Introducing therapeutic substituents of lower prices.

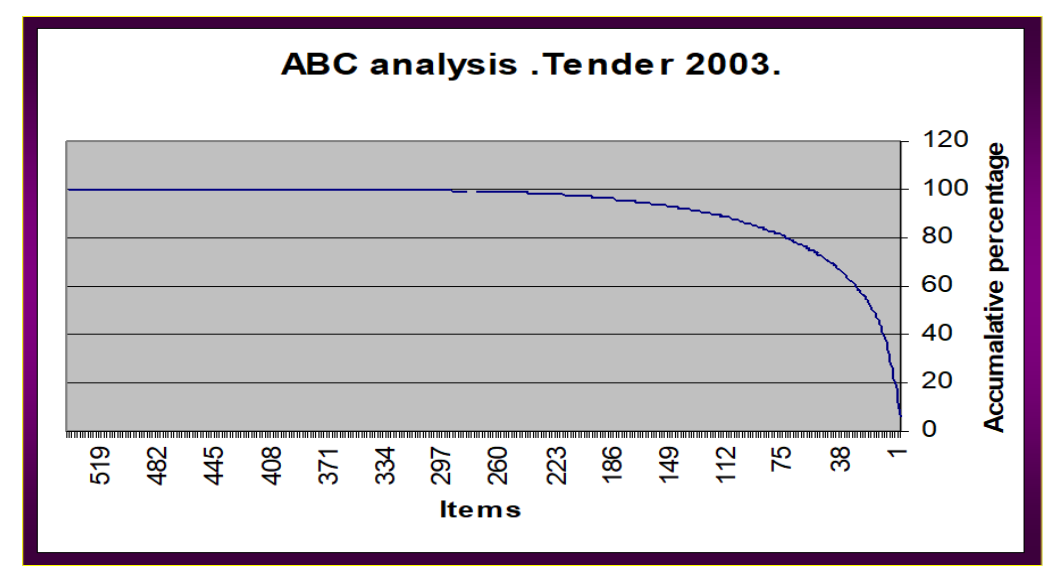

Figure 5 ABC Analysis graph.

\subsection{Therapeutic category analysis:}

The same as the ABC except that drugs are grouped into therapeutic groups. Detailed therapeutic category analysis accounts for the course of therapy of a drug within the therapeutic group. Such analysis can aid in choosing the most cost effective drugs, provides pharmacy economic information and focus on the high cost therapeutic category. With the presence of morbidity data, the expenditure of each disease could be obtained.

\subsection{Price comparison analysis [11]:}

This method focuses on the prices of the drugs within the system compared with other systems or comparing the prices obtained by different procurement methods. 


\section{Practical rational cut}

By applying $\mathrm{ABC}$ analysis and VEN analysis, the following matrix will be obtained:

\begin{tabular}{|l|l|l|}
\hline AV & BV & CV \\
\hline AE & BE & CE \\
\hline AN & BN & CN \\
\hline
\end{tabular}

Cut from categories A non-essential and B non-essential will have best impact on the budget.

\subsection{Choosing the procurement method}

In spite of being regulated by the government, it is not necessary to purchase all drugs by the same method, however, the choice should achieve the objective of the lowest possible prices and reliable supplier and good quality with minimal influences. Therefore intelligent bargaining is essential [12].

\subsubsection{Functions of the procurement committee}

- Choosing the method of purchasing.

- Defining the scope of the tender; (local or international).

- Estimate or fixed quantities and decide on registration of items.

- The policy of selecting a single supplier for each drug or split the quantities between more suppliers?

- Choose the primary/ secondary winners or primary only. If failed call for rebidding.

- If an international scope was decided; should the local agencies be involved?

- Single annual tender or multiple tenders through the year.

- Decide whether the domestic drugs should be in a separate process.

- Pre or post - qualification of bidders.

- Set the time- table of the activities.

- Decide the maximum delivery time allowed.

Group purchasing agencies and east Caribbean states use the restricted tender of pre-qualification of suppliers. Prequalification is recommended by the internal pharmaceutical federation [12]. Pre-qualification saves time. Efficient supply systems use registered items and pre-qualified suppliers list. Scheduled delivery and scheduled payment maybe useful when there is no access to funds. It is not appreciated to tender once a year when funds released in monthly installments. It is possible to use combination of two methods; e.g. negotiated fixed quantities for the bulk large single consignment and the estimated quantity method for the other products and splitting the quantities of the critical vital items. The tender could be divided into categories, each therapeutic category in a separate tender.

\subsubsection{Benefits of the involvement of local agencies offices}

- 1 / Speeds the receipt of emergency suppliers.

- 2/Improves communication with the supply system.

- 3/ Payment could be in the local currency and the supplier is foreigner.

- 4 / Participate in finding less expensive alternatives.

- 5/ Advises the producer to get competitive prices.

- 6/ Provides a legal aspects because being within one country.

- 7/ Provides information.

- 8/ Allowing the agency to oversee their products within the system.

\subsubsection{Pre- qualification and post- qualification $[13,14,15]$ :}

Suppliers could be evaluated through performance records, including responses to inquiries, participation performance delivery, shipment, documentation, packaging, shelf lives, finance and information. Quality of the products including complaint, quality assurance, packaging and certificates of new suppliers should be reviewed. Supplier information on status, quality, inspection, personnel, clients, finance and supervision should be evaluated. Public reports in its performance may be of great value. 


\subsubsection{Tender documents $[1,6]$}

- Dissemination of a fully detailed call for invitation of bidders.

- Detailed instruction in documents submission, validity of offers, prices currency, performance and bid bonds, contract conditions, the tender time table, maximum date of delivery and the technical specification.

- The sheet of requirements may be electronic and contains full details of item.

\begin{tabular}{|l|l|l|l|l|l|l|l|l|l|l|}
\hline Code number & Item & Strength & Basic unit & Quantity & Package in basic units & Standards & basic price & Delivery & Total valu Remarks \\
\hline & & & & & & & cif,cf,fob & & & \\
\hline & & & & & & & & & & \\
\hline & & & & & & & & & & \\
\hline
\end{tabular}

Figure 6 The Tender sheet

\subsection{Receiving offers:}

Four to eight weeks are open period before the closing date which should be a specific hour during the day time. Lower prices suppliers not responding, could be recalled directly.

\subsection{Adjudication}

- A transparent, sound and written procedure should be followed. All bids should be coded and the supplier name could be hidden and kept at higher authority. Formally open the offers.

- Sorting out the non-complying offers and report on them, separate apart the domestic drugs.

- Convert the prices into one common currency to equalize the freight costs and customs.

Lastly collate in an adjudication sheet for comparison. Each item in one comparison sheet should be headed by the tender number and year. The item number, description, strength, dosage form, basic unit, quantity and pallet size should be clearly mentioned.

Table 3 Comparison sheet

\begin{tabular}{l|l|l|}
\hline \multicolumn{2}{c}{ WHO required data[16] } & \multicolumn{1}{l}{ Local-CMS required data } \\
\hline 1 & \multicolumn{1}{l}{ Supplier code } & \multicolumn{1}{l|}{ Tender number } \\
\hline 2 & Bidders name & Tenderers name \\
\hline 3 & \multicolumn{1}{l}{ Country of origin } & Price for unit \\
\hline 4 & Lead time & Total cost \\
\hline 5 & Packs offered & Name of manufacturer and country of origin \\
\hline 6 & Pack size & Payment \\
\hline 7 & Pack price & Delivery \\
\hline 8 & Exchange rate & Remarks \\
\hline 9 & Pack common currency & \\
\hline 10 & ABC & \\
\hline 11 & Adjusted price & \\
\hline 12 & Total bid value & \\
\hline 13 & Comparison value & \\
\hline 14 & Remarks & \\
\hline
\end{tabular}

- The lowest price bidder that has the capacity to supply a product that meets the standards required would be awarded.

- The procurement office staff should not have a vote in the decisions, written criteria adhere to the transparency, and results should be available for all. Broadening the committee ensures that it has the final authority, enforcing transparency and rebuild credibility. A short appeal period gives confidence.

- Unit price CIF or CIP (CIP: purchaser warehouse) is an adequate mean of comparison, delivery date should be compared with the history of the supplier performance. The cost of shortage should be considered. 
- Special stated criteria: The World Bank state that up to $15 \%$ increase in price is allowed for local industry, splitting of ordered quantities protects against political changes or any disasters [12,13].

- The whole process may be computerized and special constructed computer program may be applicable.

\subsection{Contracting for drug supply [13]}

The contract is a binding document between the purchaser and the supplier. It should be clear, specific and detailed. Trade Terms, technical specifications and conditions, financial aspects and penalties, all should be clear.

- Trade terms (Incoterms); it defines the exact point where the seller's cost and responsibilities ends [12].

- Quantities: if the quantities is not fixed it is better to guarantee a minimum estimated quantity.

- Payment: the contract should specify the method of payment and currency, bidders use to add a contingency factor when the governmental payment is indefinite.

- Validity of the contract should consider the last shipment and date of last delivery.

- Quality standards should state quality assurance requirements defined and set penalties.

- The label is fully defined for each item and if extra labels in needed or unique identifier.

- Packaging: clearly specify the inner container nature and contents and the package of the outer container and the cartons and pallets dimensions. Blister or strips, trays for the ampoule or cells, plastic or glass container for liquids. Neck or one end auto breakable ampoules or not- state the defaults in packaging and penalties. Insurance for spoilage.

- Remaining period of the drug shelf life should be stated clearly. Usually $75-60 \%$ shelf life is required.

- State the delivery dates and set the penalties on delayed deliveries.

- Bid bonds and performance bonds: this could be stated according to the official regulations the World Bank stated $10 \%$ performance to be located by cash or draft or L.C with 30 days from the date of receipt of the award 13. This guarantees the liability of the supplier - particularly in the open tender process.

- The contract should state that the supplier would identify the buyer against all claims that arise on account of patent rights, trademarks, designs and royalties.

- The contract should define the defaults in all aspects of the contract and clearly define the penalties for each default and the laws to which the supplier will be subjected [2].

\subsection{Monitoring Performance}

Continuous reviewing of the product card in order to facilitates tracing of the outstanding order, each order should be numbered date of order, date of delivery, shipment and payment could be stated manually or by computer.

\subsection{Monitoring suppliers}

Tracing the lead time, compliance to contracts, follow-up the shipment, shelf life, packaging, labeling, contract value, the annual purchasing from a particular supplier and keeping a file for each supplier containing all documents received. Investigating the hidden cost is an in-depth analysis.

\subsection{Monitoring health facilities performance}

Value of drugs supplied in a year, compared with the estimated quantities, consumption and quality complaints.

Code number:

Category:

Form:

Acceptable standards:

Technical specification:
Generic name:

Trade name

Dosage:

Pack size:

Product card side I

\begin{tabular}{|l|l|l|l|l|l|l|}
\hline Order number & Supplier & Quantity & Unit price & Date promised & $\begin{array}{l}\text { Date of } \\
\text { delivery }\end{array}$ & Comments \\
\hline
\end{tabular}

Figure 7 Product card side II 


\section{Managing procurements process}

\subsection{Manager requirements}

Manager should politically supported, government commitment, modern financial management, efficient accounting system, well designed responsibilities arrangement, regular reports, regular communication with clients and suppliers, communication with the distribution department with field visits and formal training.

\subsection{Procurement office responsibilities}

- Collate information on needs of drugs.

- Developing a procurement list.

- Manage the tender process.

- Monitor supplier performance.

- Execute the decision of the selection committee.

The procurement office should not determine the supplier.

\subsection{Staff}

Staff includes directors, assistant experts and technical staff. Accountants, computer operators, one of them should be professional, clerks, secretaries and receptionist. Generally trained staffs at the key position are transferred just as they become competent at a position, they should be stable.

\subsection{Salaries}

Usually it is more cost effective to pay reasonable salaries than to implement tough regulations. Restructuring procurement office as an independent or privatized unit may be the only way for paying adequate salaries.

\subsection{Communication and market intelligence}

Collection of information in supplier reliability, quality and capacity, comparative price data and assessing the market needs, all these activities need communication fax, external telephone line, E. mail and web site.

\subsection{Procurement operational manual}

It states the written policies and procedures, job descriptions, contracting, bidding, receipt and deliveries.

\subsection{Financial sustainability}

Strategies always tend to separate drug procurement from the annual treasury cycle. When suppliers know that they will be paid immediately after delivery, price will be much more competitive.

\section{The tender committee}

It managed the tender process and decides which supplier to be contracted. It negotiates suppliers and should be highly authorized, over all decisions. Members should include representation from the selection committee, the procurement office, finance, health facilities and users. It may have subcommittee for the technical recommendations. It should be chaired by senior highest governmental level. Teaching staff maybe of great value. Medical departments, nurses and technicians better to be involved in specific specialized issues.

\section{Good pharmaceutical procurement practice GPPP [6]}

\subsection{Procurement by Generic names}

Use generic names for competition with quality standards specifications especially for those drugs that have bioavailability problems. 


\subsection{Procurement of a limited list}

No health program can afford to purchase all drugs available in the market. The formulary list or the selection committee list should avoid duplication. Make the therapeutic category analysis and use an approved formal procurement for the non-listed drugs.

\subsection{Procurement in bulk}

Focus on a limited list of increased quantities to reduce the prices besides stating divided deliveries.

\subsection{Formal supplier qualification and good monitoring}

Keep a formal list for registered qualified suppliers which should be based on quality, reliability, finance and check quantities. Track the lead time, compliance to contract, shipment, deliveries, shelf life, packaging, labeling and all conditions.

\subsection{Competitive procurement}

Use competitive method for purchasing, keeping very small emergency orders. Drug can have the minimum price when there are five generics in the market; the rule of five [2].

\subsection{Sole - source commitment}

Contracted drugs should only be purchased from the winner (Monopsy commitment).

\subsection{Reliable payment and good financial management}

Prompt payment brings down prices.

Separate drug accounts apart from the treasury cycle.

\subsection{Transparency and written procedures}

Selection, quantification, pre-qualification and award contract should be separated and filled with expertise and practicing committees for different activities.

\subsection{Quality assurance}

Maintain formal system for quality assurance (WHO certification, reporting quality problems, quality testing). Bioequivalence should be required for new supplier's products.

(WHO) defines quality assurance as the activities and responsibilities intended to ensure that products meet all the applicable quality specifications in the final dosage form. The purpose of quality assurance in a drug supply program is to ensure that the patient receives safe, effective and standard quality drugs.

\subsection{Order according to systematic qualification}

Keep records on the actual consumption and accurate morbidity and consumption should be adjusted for related factors by expert technical committee using $\mathrm{ABC}, \mathrm{VEN}$ and therapeutic category analysis.

\subsection{Annual audit with published results and regular reports $[1,16]$}

- Stock details report including expiry dates.

- Out of stock report.

- Expired stock report.

- Nearly to be expire stock report.

- Outstanding orders report.

- Reorder quantities report.

- Stock status reports by expiry dates.

- Report in differences.

- Inventory adjustment of stock.

- Supplier performance report.

- Facilities reports.

- Supplier lead time report. 
- Accounts payable report.

- Accounts receivable reports.

- Warehouse activity report.

- Tender list report.

- Currency exchange rate report.

- Tender offers report.

- Account statement.

- Adjudication report.

- List of facilities accounts by total value.

- Tender award list.

- List of facilities accounts by item value.

- Purchases by source report.

- Percentage of the emergency purchases.

- Planned purchases versus actual purchase.

- $\mathrm{ABC}$ analysis.

- Therapeutic category analysis.

- Price comparison analysis.

- Quality complaints reports

\section{Conclusion}

A perfectly selected pharmaceutical products to satisfy the health needs can be timely acquired in quantities that fulfills the health demands in an appropriate quality from a reliable suppliers which is professionally monitored with the lowest possible prices that the population can afford, through a professionally transparent procedures performed by an expertise procurement office using a scientific strategies and a sufficient managerial efforts.

\section{Compliance with ethical standards}

\section{Acknowledgments}

Author greatly acknowledges Professor Elamin Ibrahim Elnima for his valuable support.

\section{Disclosure of conflict of interest}

Author declares that, there is no any sort of conflict of interest on publishing this article.

\section{References}

[1] Hogerzeil HV. Essential Drugs and Medicines Policies. WHO Department of Essential Drugs. 2000; 1-3.

[2] Stephen Martin. Hospital Pharmacy. Pharmaceutical Press, U.K.PP. 2003; PP 74-81, 121-143.

[3] Griffiths Adrian. Estimating Drug Requirements. A Practical Manual. Director of the Health Management Institute, Geneva. Published by WHO, Action Program oh Essential Drugs. 1991; 3.2-8.5.

[4] Quick JD, et al. Managing Drug Supply: The Selection, Procurement, Distribution, and Use of Pharmaceuticals (2nd edition Revised and Expanded). Managing Science For Health in Collaboration with the WHOAction Program On Essential Drugs. USA, West Harford, Kumarian Press. 1997.

[5] Antezana FS, Velasquez G. Drug and Health System Sector Reform. WHO, a task force on health economics. 1996; 7-17.

[6] Management Science for Health, Good pharmaceutical procurement. MDS: Managing Access to Medicines and Health Technologies, Arligton, published by managent Science of Health. 2012; $18.2-18.5$

[7] MSH. Inventory Management Assessment Tool (IMAT). Imat eng.version1. 2001; 1-9.

[8] MSH. Tools and Techniques; the series of Planning for your Organization, adopting the strategic planning process ton various levels in the organization. 2003; 1-3.

[9] MSH. Guidelines for Implementing Drug Utilization Review Program in Hospitals. 2001. 
[10] MSH. Managing Pharmaceuticals and Commodities. 2000; 1-3.

[11] Dumolin J. Guide To Drug Financing Mechanism. WHO, Geneva. 1998.

[12] ITC. International Trade Centre. Stock Management. Guide No. 6, UNCTAD/ GATT. 1985; 66.

[13] World Bank. Procurement of pharmaceuticals and vaccines. Washington, DC: World Bank. Procurement Technical Note No. 4.3.2.1993.

[14] WHO. Report of Expert Committee on Essential Drugs. 1999.

[15] WHO. Rational Use of Drugs, a report of the Conference of Experts in Nairobi. WHO publications. 1985.

[16] WHO. J.Rankin, JD Quick and S. Muziki, Geneva, Essential Drugs and Medicines, Policy interagency pharmaceutical coordination group, operation principles for good pharmaceutical procurement, WHO/EDM/PAR/99.5. 1999.

[17] Brudon P, et al. Indicators For Monitoring National Drug Policies, a Practical Manual, 2nd edition. WHO. 2000; 63-145. 